\title{
Sobre o conceito de identidade: apropriações em estudos sobre formação de professores
}

\author{
Ederson de Faria \\ Vera Lúcia Trevisan de Souza
}

\begin{abstract}
Resumo
Esse artigo resulta de uma pesquisa em que se buscou compreender como o conceito de identidade tem sido apropriado nas pesquisas sobre formação de professores e sua contribuição para a compreensão do processo de constituição da identidade docente. Foram analisadas cinco dissertações de mestrado e cinco teses de doutorado que apresentavam, no título e no resumo, a proposta de estudar identidade de professores. O método utilizado foi o estudo bibliográfico, tomando-se, como referentes teóricos, os autores que desenvolvem estudos sobre identidade. Como resultado, constatou-se que algumas pesquisas realizadas no âmbito do mestrado e doutorado têm recorrido a conceitos de vários autores da Sociologia e de um autor da Psicologia, os quais oferecem subsídios para a compreensão do fenômeno da constituição identitária do professor. Palavras-chave: Identidade, formação de professores, psicologia educacional.
\end{abstract}

\section{The identity concept and its appropriation in teachers education studies}

\begin{abstract}
This article is the result of a research that attempts to understand how the identity concept has been appropriated in teachers' education studies and their contribution to the understanding of the process of identity constitution. We analyze five Master's theses and five doctoral dissertations that revealed through their titles and summaries the proposal to study teachers' identities. We conducted a bibliographical research, taking as theoretical references authors who use cultural-historical approach. We found that some research pieces carried out by MA and PhD candidates have used the concepts of several authors in the field of sociology and an author in psychology. These scholars provide us with input for understanding the phenomenon of the teacher's identity construction .
\end{abstract}

Keywords: Identity, teachers' education, educational psychology.

\section{Sobre el concepto de Identidad: apropiaciones en estudios sobre formación de profesores}

\section{Resumen}

Este artículo resulta de una investigación en la que se buscó comprender como el concepto de identidad está apropiado en las investigaciones sobre formación de profesores y cuál su contribución para la comprensión del proceso de constitución de la identidad docente. Se analizaron cinco tesis de maestría y cinco tesis doctorales que presentaban en el título y en el resumen la propuesta de estudiar identidad de profesores. El método utilizado fue el de estudio bibliográfico, tomándose como referentes teóricos los autores que desarrollan estudios sobre Identidad. Como resultado se constató que algunas investigaciones de maestría y doctorado recurrieron a conceptos de varios autores de Sociología y de un autor de Psicología, los cuales ofrecen subsidios para la comprensión del fenómeno de la constitución de identidad del profesor.

Palabras Clave: Identidad, formación de profesores, psicología educacional. 


\section{Introdução}

Neste artigo, são apresentados os resultados de um estudo que buscou investigar o conceito de identidade utilizado nas pesquisas sobre formação de professores, tendo em vista o crescimento das pesquisas na área da Psicologia e da Educação voltadas à investigação desse tema.

Nosso interesse pelo tema da identidade nasce de um projeto de pesquisa desenvolvido pelo Grupo de Pesquisa "Processos de constituição do sujeito em práticas educativas", do Programa de Pós-Graduação em Psicologia da PUC de Campinas, cujo objetivo era investigar a constituição identitária de professores, entendendo que as representações que esses profissionais têm de si como docentes interferem em sua prática pedagógica e nas relações que desenvolvem com os sujeitos do espaço escolar.

$\mathrm{Na}$ pesquisa que ora apresentamos, nos dedicamos, primeiramente, a compreender e discutir o conceito de identidade formulado por alguns autores da Psicologia e da Sociologia, tendo em vista sua apropriação nas pesquisas que estudam formação de professores para, em um segundo momento, identificar e analisar em estudos do nível do mestrado e do doutorado em que medida os conceitos utilizados por seus autores têm se constituído como aporte à compreensão e explicação dos fenômenos estudados.

\section{As pesquisas sobre formação de professores e o tema da identidade}

Não é difícil encontrar, na literatura científica, trabaIhos cujo propósito é discutir, problematizar, quantificar e classificar a formação de professores. Além da Educação, outras áreas do conhecimento têm se preocupado com esse tema; a produção de pesquisas é extensa na Psicologia e a questão também tem despertado o interesse de sociólogos, filósofos e historiadores. Em pesquisa do tipo estado da arte, André (1999) analisa a produção acadêmica sobre formação de professores no período de 1990 a 1996, e encontra, somente na área da Educação, 284 estudos sobre o tema. Constata a autora que o tema da identidade é pouco estudado, correspondendo a 9\% do total de dissertações e teses constantes do banco da CAPES no período. Contudo, em nova pesquisa de mesma natureza, focalizando a produção no período de 1999 a 2003, a autora identifica 1184 pesquisas sobre formação de professores, revelando um crescente interesse sobre o tema. Desse total de estudos analisados, $13 \%$ abordam o tema da identidade, o que evidencia um aumento do interesse de pesquisadores desse campo sobre a problemática da constituição da identidade docente (André, 2009).

Os dados dessas pesquisas, somados ao conhecimento dos objetivos declarados nas primeiras pesquisas que acessamos, permitiram constatar que o interesse crescente em estudos sobre identidade no campo da formação docente indica que sua compreensão pode trazer contribuições ao campo da formação e, em consequência, à educação escolar. Tal constatação nos levou a questionar as pers- pectivas teóricas que têm sido adotadas nesses estudos, por entendermos ser um tema de interesse do campo da Psicologia. Nossa hipótese era que a análise do referencial teórico das pesquisas permitiria avaliar a contribuição de teorias da Psicologia ao campo de estudos sobre a formação de professores.

\section{O conceito de identidade}

Conforme anunciado, passamos a apresentar o conceito de identidade das perspectivas da Psicologia e da Sociologia, visto serem essas as abordagens adotadas nos estudos que analisamos. Inicialmente, apresentamos os postulados teóricos de Antonio da Costa Ciampa, que aborda a identidade como categoria da Psicologia Social. O autor realizou um estudo que se tornou referência sobre o tema, em que se utiliza do materialismo histórico como base teórica e do método dialético para sua construção.

Em seguida, discorremos sobre os conceitos de identidade desenvolvidos por Claude Dubar, sociólogo francês que estuda identidade no trabalho e que é o mais utilizado nas teses de doutorado sobre identidade que analisamos. Ainda da perspectiva da Sociologia, apresentamos os postulados sobre identidade de dois outros autores, também utilizados nas teses de doutorado. Trata-se de Zygmunt Bauman, sociólogo polonês que se preocupa com o tema focalizando o que denomina de modernidade líquida, e do inglês Stuart Hall, também sociólogo, que estuda as identidades culturais da perspectiva da pós-modernidade.

Ciampa (1987) entende identidade como metamorfose, ou seja, em constante transformação, sendo o resultado provisório da intersecção entre a história da pessoa, seu contexto histórico e social e seus projetos. A identidade tem caráter dinâmico e seu movimento pressupõe uma personagem. A personagem, que, para o autor, é a vivência pessoal de um papel previamente padronizado pela cultura, é fundamental na construção identitária: representa-se a identidade de alguém pela reificação da sua atividade em uma personagem que, por fim, acaba sendo independente da atividade. As diferentes maneiras de se estruturar as personagens resultam diferentes modos de produção identitária. Portanto, identidade é a articulação entre igualdade e diferença.

Identidade é movimento, porém, uma vez que a identidade pressuposta é reposta pelos ritos sociais, passa a ser vista como algo dado e não como se dando. A reposição, portanto, sustenta a mesmice, que é a ideia de que a identidade é atemporal e constante: identidade-mito. A superação da identidade pressuposta denomina-se metamorfose (Ciampa, 1987).

Dubar (1997) concebe identidade como resultado do processo de socialização, que compreende o cruzamento dos processos relacionais (ou seja, o sujeito é analisado pelo outro dentro dos sistemas de ação nos quais os sujeitos estão inseridos) e biográficos (que tratam da história, habilidades e projetos da pessoa). Para ele, a identidade para si não se separa da identidade para o outro, pois a primeira é correlata à segunda: reconhece-se pelo olhar do outro. 
Porém, essa relação entre ambas é problemática, pois não se pode viver diretamente a experiência do outro, e ocorre dentro do processo de socialização.

O autor afirma que a "identidade nunca é dada, é sempre construída e a (re) construir, em uma incerteza maior ou menor e mais ou menos durável" (Dubar, 1997, p. 104). Essa afirmação o aproxima de Ciampa (1987), quando diz que a identidade se constrói na e pela atividade.

A identificação vem do outro, mas pode ser recusada para se criar outra. De qualquer forma, a identificação utiliza categorias socialmente disponíveis (Dubar, 1997).

O processo de constituição da identidade, para Dubar (1997), que prefere falar em formações identitárias, visto entender que são várias as identidades que assumimos, se constitui em um movimento de tensão permanente entre os atos de atribuição (que correspondem ao que os outros dizem ao sujeito que ele é e que o autor denomina de identidades virtuais) e os atos de pertença (em que o sujeito se identifica com as atribuições recebidas e adere às identidades atribuídas). Enquanto a atribuição corresponde à identidade para o outro, a pertença indica a identidade para si, e o movimento de tensão se caracteriza, justamente, pela oposição entre o que esperam que o sujeito assuma e seja e o desejo do próprio sujeito em ser e assumir determinadas identidades. Logo, o que está no cerne do processo de constituição identitária, segundo o autor, é a identificação ou não identificação com as atribuições que são sempre do outro, visto que esse processo só é possível no âmbito da socialização.

Dubar (1997) sintetiza a constituição das formas identitárias a partir da ocorrência de dois processos: o relacional e o biográfico. O primeiro diz respeito à identidade para o outro, em que as transações assumem um caráter mais objetivo e genérico; enquanto o biográfico corresponde à identidade para si, cujas transações são mais subjetivas, e compreende as identidades herdadas e identidades visadas. Desse modo, os processos relacional e biográfico concorrem para a produção das identidades. A identidade social é marcada pela dualidade entre esses dois processos e a dialética estabelecida entre eles é o cerne da análise sociológica da identidade para esse autor.

Também da perspectiva da Sociologia, mas com foco na pós-modernidade, Bauman (2005) define identidade como autodeterminação, ou seja, o eu postulado. Para ele, as identidades comumente referem-se às comunidades como sendo as entidades que as definem. Existem dois tipos de comunidades: as de vida e destino, nas quais os membros vivem juntos em uma ligação absoluta, e as comunidades de ideias, formadas por uma variedade de princípios. A questão da identidade só se põe nas comunidades do segundo tipo, onde há a presença de diferentes ideias e, por isso, também a crença na necessidade de escolhas contínuas.

Identidade se revela como invenção e não descoberta; é um esforço, um objetivo, uma construção. É algo inconcluso, precário, e essa verdade sobre a identidade está cada vez mais nítida, pois os mecanismos que a ocultavam perderam o interesse em fazê-lo, visto que, atualmente, interessa construir identidades individuais, e não coletivas. Esse fato, contudo, é recente. O pensar sobre se ter uma identidade não ocorre enquanto se acredita em um pertencimento, mas quando se pensa em uma atividade a ser continuamente realizada. Essa ideia surge da crise do pertencimento (Bauman, 2005).

A essência da identidade constrói-se em referência aos vínculos que conectam as pessoas umas às outras e considerando-se esses vínculos estáveis. O habitat da identidade é o campo de batalha: ela só se apresenta no tumulto. Não se pode evitar sua ambivalência: ela é uma luta contra a dissolução e a fragmentação, uma intenção de devorar e uma recusa a ser devorado. Essa batalha a um só tempo une e divide, suas intenções de inclusão e segregação misturam-se e complementam-se (Bauman, 2005).

$\mathrm{Na}$ modernidade líquida, há uma infinidade de identidades à escolha, e outras ainda para serem inventadas (Bauman, 2005). Com isso, só se pode falar em construção identitária enquanto experimentação infindável.

Da mesma perspectiva que Bauman, mas interessado na identidade cultural, Stuart Hall (2006) apresenta o conceito do que denomina "identidades culturais" como aspectos de nossas identidades que surgem de nosso "pertencimento" a culturas étnicas, raciais, linguísticas, religiosas e, acima de tudo, nacionais. O autor entende que as condições atuais da sociedade estão "fragmentando as paisagens culturais de classe, gênero, sexualidade, etnia, raça e nacionalidade que, no passado, nos tinham fornecido sólidas localizações como indivíduos sociais". (p. 9) Tais transformações estão alterando as identidades pessoais, influenciando a ideia de sujeito integrado que temos de nós próprios: "Esta perda de sentido de si estável é chamada, algumas vezes, de duplo deslocamento ou descentração do sujeito" (Hall, 2006, p. 9). Esse duplo deslocamento, que corresponde à descentração dos indivíduos tanto de seu lugar no mundo social e cultural quanto de si mesmos, é o que resulta em "crise de identidade".

Hall cita o crítico cultural Kobena Mercer, para quem "a identidade somente se torna uma questão quando está em crise, quando algo que se supõe como fixo, coerente e estável é deslocado pela experiência da dúvida e da incerteza" (Mercer, 1990, p.43).

Segundo Hall (2006), há três diferentes concepções de identidade que se relacionam às visões de sujeito ao longo da história. A primeira é denominada identidade do sujeito do Iluminismo, que expressa uma visão individualista de sujeito, caracterizado pela centração e unificação, em que prevalece a capacidade de razão e de consciência. Assim, entende-se o sujeito como portador de um núcleo interior que emerge no nascimento e prevalece ao longo de todo seu desenvolvimento, de forma contínua e idêntica. Já a segunda, a identidade do sujeito sociológico, considera a complexidade do mundo moderno e reconhece que esse núcleo interior do sujeito é constituído na relação com outras pessoas, cujo papel é de mediação da cultura. Nessa visão, que se transformou na concepção clássica de sujeito na Sociologia, o sujeito se constitui na interação com a sociedade, em um diálogo contínuo com os mundos interno e externo. Ainda permanece o núcleo interior, mas este é constituído pelo social, ao mesmo 
tempo em que o constitui. Assim, o sujeito é, a um só tempo, individual e social; é parte e é todo.

Por último, apresenta a concepção de identidade do sujeito pós-moderno, que não tem uma identidade fixa, essencial ou permanente, mas formada e transformada continuamente, sofrendo a influência das formas como é representado ou interpretado nos e pelos diferentes sistemas culturais de que toma parte. A visão de sujeito assume contornos históricos e não biológicos, e o sujeito adere a identidades diversas em diferentes contextos, que são, via de regra, contraditórias, impulsionando suas ações em inúmeras direções, de modo que suas identificações são continuamente deslocadas. Frente à multiplicidade de significações e representações sobre o que é o homem na pós-modernidade, o sujeito se confronta com inúmeras e cambiantes identidades, possíveis de se identificar, mas sempre de forma temporária. Logo, o sujeito pós-moderno se caracteriza pela mudança, pela diferença, pela inconstância, e as identidades permanecem abertas. Apesar desta visão de sujeito soar como perturbadora, visto seu caráter de incerteza e imprevisibilidade resultante do deslocamento constante, segundo Hall (2006), ela tem características positivas, pois se, de um lado, desestabiliza identidades estáveis do passado, de outro, abre-se a possibilidade de desenvolvimento de novos sujeitos.

Foram muitos os fatos e aspectos que influenciaram essa mudança de entendimento do sujeito ao longo da história e que continuam a provocar transformações no momento atual, em que adventos como a globalização imprimem uma nova dimensão temporal e espacial na vida dos sujeitos.

Para Hall (2006), identidades correspondentes a um determinado mundo social estão em declínio, visto que a sociedade não pode mais ser vista como determinada, mas em contínua mutação e movimento, fazendo com que novas identidades surjam continuamente, em um processo de fragmentação do indivíduo moderno. Assim, assinala que estaria ocorrendo uma mudança no conceito de identidade e de sujeito, já que as identidades modernas estão sendo "descentradas", ou seja, deslocadas e fragmentadas e, como consequência, não é possível oferecer afirmações conclusivas sobre que é identidade, visto tratar-se de um aspecto complexo, que envolve múltiplos fatores.

O autor também destaca o caráter de mudança no que chama de modernidade tardia, expressão utilizada por Giddens para referir ao que alguns sociólogos têm chamado de pós-modernidade. Logo, as sociedades modernas têm como característica a mudança constante, rápida e permanente, o que se constitui como principal diferença das sociedades tradicionais.

Assim, a modernidade tardia não se define somente como experiência de convivência com a mudança rápida, abrangente e contínua, mas como uma forma altamente reflexiva de vida, em que as informações promovem uma constante avaliação e transformação das práticas sociais e alteram constitutivamente suas características e, por conseguinte, as identidades em relação. Em síntese, para esse autor, identidade, sociedade e cultura não se separam.
Importa esclarecer que não se pretendeu, com a exposição realizada nas páginas precedentes, esgotar o tema da identidade, identificando e apresentando todos os autores que o têm abordado. Ou seja, não se trata de um estudo do tipo estado da arte, mas de relacionar e discutir alguns teóricos que têm se dedicado ao estudo do tema, sobretudo com foco na definição do conceito de identidade. Assim, o critério de escolha dos autores levou em conta o fato de se constituírem como aportes teóricos às pesquisas que têm sido desenvolvidas e considerou-se, ainda, a pertinência de seus trabalhos, no que concerne ao investimento e consistência ou repercussão dos mesmos e ao seu caráter psicossocial. Reconhecemos, assim, que vários autores não foram contemplados nessa análise, como os do campo da Psicanálise, por exemplo; contudo, acreditamos que os escolhidos representam as perspectivas teóricas psicossociais que têm se dedicado à definição do conceito.

\section{Método e procedimentos}

Essa pesquisa é de natureza bibliográfica na medida em que toma, como fonte de dados, registros disponíveis decorrentes de pesquisas anteriores, em meio impresso ou digital, em forma de artigos científicos, dissertações ou teses. Os textos dessas pesquisas constituem-se fontes de dados que o pesquisador utiliza para o seu trabalho, visto apresentar categorias teóricas já trabalhadas (Severino, 2007).

Seu caráter é descritivo, pois não será realizada pesquisa de campo para comprovar os dados obtidos, pelo contrário, serão analisados trabalhos já realizados por pesquisadores, visando comparar dados e checar informações.

O trabalho foi dividido em dois momentos. Inicialmente, fez-se um levantamento dos autores que têm estudado o conceito de identidade e selecionamos suas produções mais significativas. Em seguida, buscamos, no banco da CAPES, teses e dissertações produzidas nos últimos três anos, usando os descritores identidade e formação de professores. Lemos os resumos dos trabalhos encontrados e identificamos, naqueles que explicitavam o referencial teórico, as teorias que estavam sendo adotadas nas pesquisas. A partir de então, definimos as teorias sobre identidade que iríamos estudar. Feita a escolha das obras, procedeu-se a uma leitura aprofundada dos conceitos com vista à sua análise e proposições de explicações para o tema da identidade.

Em seguida, selecionamos cinco dissertações e cinco teses produzidas em Programas de Pós-Graduação em Psicologia e Educação nos últimos três anos (exceto a tese de doutoramento de Conti, datada do ano de 2003), que apresentavam, no título e no resumo, a proposta de estudar identidade no âmbito da formação de professores. A escolha de um número limitado de trabalhos deveu-se ao tempo para realização da pesquisa, um ano, e ao fato dos objetivos da pesquisa exigirem a leitura e a análise do referencial teórico adotado, atividades que levam tempo considerável para serem realizadas. 
Como critério de escolha dos trabalhos, além dos já apresentados (identidade e formação de professores e programas de Psicologia e Educação), teve grande peso a possibilidade de acesso à pesquisa completa, tendo em vista que, em muitos casos, somente os resumos são disponibilizados, o que não permitiria a realização da análise proposta.

As dissertações foram todas produzidas em universidades sediadas no Estado de São Paulo, sendo duas delas em universidades públicas estaduais e as demais, em duas diferentes instituições confessionais.

Em relação às teses, quatro são do Estado de São Paulo e uma é do Estado do Rio Grande do Sul. Duas das teses paulistas são de uma universidade pública estadual e as demais foram produzidas em instituições confessionais.

Selecionadas as pesquisas, partiu-se para a leitura e análise dos seus referenciais teóricos a fim de se verificar como o conceito de identidade foi apropriado por elas. Focou-se apenas a abordagem teórica dessas pesquisas e não os seus resultados.

Para o propósito deste artigo, apresentamos a seguir dois eixos de análise que sintetizam o que se objetivou com o presente estudo: objetivos do trabalho e sua relação com a apropriação do conceito de identidade; e referencial teórico ou conceito de identidade: a relação entre o conceito e sua contribuição para os estudos sobre formação de professores.

\section{Resultados e discussões}

\section{Objetivos do trabalho}

No que concerne aos objetivos declarados pelos autores, é possível observar a busca pela compreensão do processo de desenvolvimento profissional de educadores, tendo como foco o sujeito e sua relação com a docência. A análise dos objetivos permite constatar que algumas pesquisas focalizam o professor em exercício, expressando a ideia de identidade como processo de constituição permanente, caracterizado por movimento de afirmação e negação: "Analisar como o ser-professor se narra e interpreta-se como sujeito na profissão, tendo em vista compreender de que maneira esse profissional constrói a identidade pessoal/ profissional, sendo capaz de afirmar-se ou negar-se como sujeito dentro do sistema-escola" (Ferreira, 2006).

Contudo, há também a compreensão de que a identidade se constrói no processo de formação inicial, sobretudo no contato do futuro professor com a prática profissional, ou seja, a atividade docente que marcaria trajetórias diferenciadas de identidade: "Relatar e compreender como se constitui a identidade docente em processo de formação, destacando a prática como elemento formador e diferenciador das trajetórias de identidade." (Freitas, 2006)

No trabalho de Assis (2007), a amplitude que parece atingir a ideia de identidade refere-se também a cursos, ou seja, organizações curriculares que assumiriam determina- das características que se pode chamar de identidade. Contudo, o objetivo expresso pelo autor carece de clareza, não sendo possível identificar, com precisão, identidade do que ou de quem se propõe a pesquisar:

Reconhecer o papel do curso de Pedagogia no Brasil, que profissional forma e qual a sua identidade, considerando os segmentos formativos pouco articulados de profissionais da gestão educacional e professores das séries iniciais de ensino fundamental e educação infantil. (Assis, 2007)

Há, também, a pressuposição de que a identidade se constrói no processo de formação continuada a ser desenvolvido pela escola, indicando que a constituição da identidade pessoal e profissional são processos concomitantes que deveriam ser preocupação da formação em exercício: "Identificar as possíveis contribuições do processo de formação permanente realizado pela instituição na constituição das identidades pessoais e profissionais de educadoras pesquisadoras." (Buccini, 2007).

Entretanto, de caráter mais ampliado, há objetivos que visam estudar a identidade ao longo de uma trajetória, com foco na profissionalização e percorrendo todo o caminho de escolha da profissão até sua efetivação nas ações educativas: "Pretendem-se reconhecer e analisar traços identitários construídos e reconstruídos ao longo do processo de profissionalização desde a escolha da profissão, formação inicial, inserção profissional e práxis educacional." (Pandolpho, 2006)

Já em um movimento que pretende aprofundar o conhecimento da identidade docente, se inscreve a pesquisa a seguir, em que se supõe haver uma dimensão espiritual como constituinte da identidade docente: "Compreender como a dimensão da espiritualidade contribui e participa da constituição identitária de professores e, como, em uma escola confessional, se dá essa constituição." (Vieira, 2009)

Já a tese cujo objetivo apresentamos a seguir supõe uma relação entre concepção de docência e formação identitária, e focaliza a pesquisa em uma área de atuação específica, além do segmento de ensino diferenciado: trata-se do Ensino Superior. Esse fato também revela que o interesse pela identidade docente ultrapassa a escola de educação básica, onde, frequentemente, vemos a questão da formação de professores mais debatida, e chega ao Ensino Superior: "Apreender a concepção de docência de um grupo de professores da área da Saúde e verificar as suas configurações identitárias docentes, construídas nas trajetórias pessoais e profissionais." (Pagnez, 2007)

O objetivo declarado na pesquisa de Conti (2003) não contém a expressão identidade, apenas a sugerindo na medida em que se propõe a investigar as visões da profissão docente e suas características. Logo, atrela o processo de constituição de identidade às visões que professores iniciantes têm da profissão: "Investigação das visões sociais expressas por um conjunto de seis professoras iniciantes acerca da profissão docente, mais particularmente do tipo de qualificação que a caracteriza e a define." (Conti, 2003.) 
O objetivo da pesquisa a seguir traz elementos novos atrelados ao termo identidade: memórias. Também parece interessado em investigar a questão da identidade em outro espaço que não a escola. Logo, amplia o escopo de interesses sobre o tema: "Perceber e compreender como são produzidas as práticas de memórias/identidades, por meio das manifestações coletivas desenvolvidas nesses fóruns acadêmicos nacionais." (Mesquita, 2008).

Por fim, o objetivo da última pesquisa selecionada só permite identificar que se trata de pesquisa sobre identidade, entendendo-a como percurso, visto que o pesquisador vincula a tese à sua pesquisa de mestrado e os objetivos não permitem compreender a que segmento de ensino ou instância educacional se vincula a pesquisa: "Investigar o percurso identitário de quatro professores que estiveram envolvidos anteriormente em minha pesquisa de mestrado." (Pereira, 2007)

O que se pode afirmar a partir dos objetivos apresentados é que eles confirmam o interesse de pesquisadores sobre o tema da identidade docente, sobretudo nos últimos três anos, o que nos conduz a perguntar a respeito do porquê do interesse, aparentemente recente, sobre o tema, o que as próprias pesquisas nos ajudam a responder, quando declaram acreditar que compreender a constituição da identidade do professor permitirá desvelar aspectos relativos às práticas docentes e propor melhores formas de atuação dos cursos de formação de professores, além da melhoria das práticas educativas.

Contudo, o que fica evidente é certa dispersão das pesquisas, seja no que concerne ao espaço da docência focalizado (ora no Ensino Fundamental, ora no Ensino Superior, ora na formação inicial, ora na formação continuada, ora em fóruns de discussão), ou no próprio modo de conceber a identidade: como construída na formação inicial, como processo contínuo, como trajetórias, como memórias, como visões e concepções, como aspecto pessoal ou aspecto profissional. Tal fato nos leva a questionar a relação entre essas problemáticas de pesquisa e esses diversos focos de interesse com o referencial teórico adotado pelos pesquisadores, visto que um problema de pesquisa nasce do questionamento da realidade a partir de dada forma de compreendê-la, ou seja, a abordagem do problema e o desenvolvimento do método para investigá-lo não se separam das proposições teóricas que os sustentam. Dito de outra forma, para compreender a identidade docente, é preciso buscar os postulados conceituais que sustentem tal compreensão, o que demanda acessar conceitos que, no caso do presente estudo, têm sido produzidos pela área da Psicologia e da Sociologia.

\section{Referencial teórico ou conceito de identidade: a relação entre o conceito e sua contribuição para os estudos sobre formação de professores}

Conforme anunciado nas páginas precedentes, pretende-se apresentar, neste eixo de análise, os aportes teóricos utilizados pelos autores da pesquisa e suas contribuições para aspectos que envolvem a constituição da identidade docente.
Das cinco dissertações de mestrado selecionadas, apenas duas preocupam-se com a apresentação e fundamentação do conceito de identidade de uma perspectiva científica: a de Ferreira (2006) e Freitas (2006). A dissertação de Buccini (2007) chega a citar Ciampa (1987), autor que desenvolveu o conceito de identidade da perspectiva da Psicologia, porém não apresenta os fundamentos de sua teoria. Já as dissertações de Assis (2007) e Pandolpho (2006) não apresentam referencial teórico acerca da identidade, embora tratem do conceito.

As dissertações de Ferreira (2006) e Freitas (2006) trazem postulações sobre identidade na perspectiva de Ciampa (1987), cuja obra data de 1986. Tal escolha devese ao fato da teoria desse autor oferecer grande lastro para a compreensão dos processos que constituem o sujeito, ao eleger a atividade, a memória (história) e a consciência como aspectos que se imbricam no movimento de representação de si. Em se tratando de professores, cujas práticas têm sido questionadas e criticadas por suas características de não mudança, olhar para a ação docente da perspectiva da teoria de Ciampa permitiria compreender o que estaria na base da aparente não mudança e vislumbrar ações para a formação que promovessem a conscientização dos professores sobre sua atividade, situando a história individual e social, o que poderia resultar em metamorfose.

Um aspecto preocupante concerne às outras três dissertações analisadas, que declaram, em seus objetivos, o propósito de estudar identidade e não apresentam qualquer autor que trate do tema. Apresentam referenciais da formação de professores e se utilizam do termo identidade da perspectiva do senso comum. Esse fato chama a atenção para o cuidado que se deve ter com as pesquisas, visto se tratar de produção científica que pressupõe a disseminação do conhecimento acumulado sobre dada temática. Contudo, esse fato também pode justificar a dispersão que apontamos na análise dos objetivos e certo desconhecimento teórico sobre a temática da identidade.

Notou-se, em relação às teses, uma preocupação maior com o embasamento teórico do conceito, o que se justifica por se tratar de teses de doutorado, tipo de pesquisa em que há uma exigência maior com relação à definição dos aportes teóricos que sustentam a investigação. Nas teses de Vieira (2009) e Pereira (2007), são utilizados mais de um teórico para dar fundamento ao conceito: a primeira fundamenta-se nas teorias de Dubar (1997) e Bauman (2005), e a segunda, em Dubar (1997) e Stuart Hall (2006). Apenas no trabalho de Conti (2003) se notou menos investimento do pesquisador em trabalhar o conceito, embora, ainda assim, o autor da pesquisa faça referência a Claude Dubar (1997), sem, no entanto, aprofundar-se ou discutir o conceito de identidade, o que é compreensível tendo em vista seu objetivo de estudar as visões sobre a docência e a caracterização da profissão.

Mesquita (2008) fundamenta-se nos postulados de Bauman, que, como se viu na primeira parte deste artigo, entende a identidade como mutação permanente. Assim, retomando o objetivo desta pesquisa, que se propunha a investigar as memórias/identidades em fóruns acadêmicos, 
é possível que a teoria escolhida possa fornecer explicações ao que pretende o autor. No entanto, a pouca clareza do objetivo impede relações ou conclusões mais precisas sobre a relação entre o referencial teórico e os objetivos da pesquisa.

Já a escolha de Pagnez (2007) da teoria de Dubar como referente parece muito adequada ao objetivo de estudar a identidade profissional por meio das trajetórias dos docentes, visto que o autor entende que o trabalho está no centro da constituição identitária e que as identidades se constroem nas transações objetivas e subjetivas que caracterizam a vida pessoal e profissional dos sujeitos.

O mesmo pode-se afirmar sobre Pereira (2007), que elege Dubar e Stuart Hall como referentes para atingir o objetivo de compreender a trajetória de constituição identitária de quatro professoras. Também está interessada em estudar identidade no trabalho e toma sua construção como trajetória, além de considerar o contexto cultural em que desenvolvem suas práticas.

Já Vieira (2009), que visa compreender o aspecto espiritual na constituição identitária, toma como aportes Dubar e Bauman, nos levando a questionar em que medida esses autores permitem compreender a dimensão que pretendeu investigar, sobretudo porque Dubar (1997) assume a perspectiva dialética e materialista que estão na base de suas postulações.

A análise dos aportes teóricos utilizados nas teses nos leva a concluir que a forma como esses autores que estudam identidade no trabalho (Dubar), identidade na pós-modernidade (Bauman) ou identidades culturais (Hall) oferece fundamentos para a compreensão da constituição da identidade docente, visto considerarem essa constituição como dinâmica e em constante movimento, em que o sujeito se confronta com as mudanças e busca novas formas de identificação. Logo, se, de um lado, Ciampa se ocupa da constituição da identidade do sujeito, de outro, Dubar se dedica ao estudo das identidades profissionais, inserindo o trabalho como condição e fonte dessa constituição. Bauman e Hall, por sua vez, inserem as transformações sociais e culturais como fontes e condicionantes da forma como o sujeito se vê e se narra.

Assim, é possível depreender, dessa análise, que a articulação entre esses autores permitiria uma compreensão mais ampla dos processos envolvidos no movimento de se tornar professor.

\section{Considerações finais}

A partir da análise realizada, é possível afirmar que permanece como desafio o desenvolvimento de um conceito de identidade que considere os aspectos apresentados pelos diferentes autores que têm investido em seu estudo. Se, como se viu nessa breve pesquisa, a Sociologia traz grandes contribuições à explicação dos fenômenos que constituem o sujeito, por certo também o faz a Filosofia ou a Psicanálise, cujas produções não foram acessadas nessa pesquisa. Contudo, talvez o interesse crescente pelo tema possa ser explicado tomando-se por base o que afirma Stu- art Hall (2006), quando diz que o sujeito pós-moderno se caracteriza pela mudança, diferença e inconstância, mantendo sua identidade aberta, e que se, de um lado, essa visão é perturbadora pelo seu caráter de imprevisibilidade, de outro, é positiva por desestabilizar identidades do passado e abrirse à possibilidade de desenvolvimento de novos sujeitos. Mas que tipo de investigação, com que método, postura do pesquisador e delineamento seria capaz de apreender fenômeno tão móvel, inconstante, mutante e líquido?

Nas pesquisas analisadas, o estudo do tema se justifica por se acreditar em sua plausibilidade na explicação de processos que envolvem a docência, especialmente no que concerne ao modo de ser professor.

Acredita-se, por conseguinte, que a compreensão do processo de constituição identitária do professor traria contribuições para sua formação e melhoria de sua prática nas instituições, o que resultaria em melhor qualidade do ensino.

Tendo a pesquisa objetivado, em um primeiro momento, estudar o conceito de identidade em suas diferentes significações teóricas e a contribuição de diferentes teóricos na discussão e construção dos significados desse conceito, foram analisados os postulados de Ciampa (1987), Dubar (1997), Bauman (2005) e Stuart Hall (2006). O primeiro apresenta uma teoria sobre a identidade e sua constituição da perspectiva da Psicologia Social, adotando como aporte teórico o materialismo histórico-dialético. O segundo, sociólogo francês, tem desenvolvido, em seu país, estudos sobre a constituição das identidades profissionais, assumindo, também, a dialética como fundamento para explicar o movimento de sua constituição. O terceiro, sociólogo polonês, aborda a questão da identidade da perspectiva da pós-modernidade e, ainda que não declare, é possível vislumbrar traços da teoria da complexidade no modo como concebe a constituição da identidade do sujeito ao analisar como a condição pós-moderna, sobretudo as incertezas e a fluidez dos acontecimentos, afetam a identidade das pessoas. $O$ quarto, à semelhança de Bauman, também se interessa pelas mudanças da sociedade, mas focaliza a cultura.

Se, por um lado, esses autores nos possibilitam aproximar seus conceitos para compreender o fenômeno da identidade, de outro, é necessário atentar para suas diferenças e especificidades, que deverão nortear os enfoques de pesquisas sobre o tema. Ciampa (1987) ocupa-se da identidade enquanto conjunto das personagens que atuam em um processo de tensão permanente com os papéis sociais pré-estabelecidos e se transformam, ainda que algumas vezes, a aparência seja de não mudança. Dubar (1997) focaliza a identidade no trabalho, enfatizando o eixo relacional pelo estudo do papel das instituições em sua constituição, localizando as forças que atuam em sua produção também de uma perspectiva dialética em que a identidade equivale a um processo de tensão permanente entre o individual e o social. Já Bauman (2005) e Hall (2006) situam a identidade na pós-modernidade, que Bauman denomina de modernidade líquida, na qual a fixidez dá lugar à incerteza, as identidades do passado são sobrepostas pelas possibilidades 
de futuro e o sujeito se caracteriza como descentramento e deslocamento permanente.

Não obstante, há que se notar que os quatro concebem identidade como complexa, inacabada, resultando do processo constante de tensão entre o sujeito histórico e as condições materiais em que vive. Portanto, identidade como síntese de uma tensão dialética jamais findável.

Contudo, como esforço de síntese do que discutimos e analisamos, reconhecemos que o conceito de identidade sofre de certa dispersão semântica, permanecendo como desafio a todos os campos de conhecimento que se propõem a investigá-lo. Por hora, parece pertinente assumir a definição de Stuart Hall (2006): não é possível oferecer afirmações conclusivas sobre o que é identidade, visto tratar-se de aspecto complexo, que envolve múltiplos fatores.

\section{Referências}

André, M. e cols. (1999). Estado da arte da formação de professores no Brasil. Educação e Sociedade, 20(68), 301-309.

André, M. e cols. (2009). A produção acadêmica sobre formação de professores: um estudo comparativo das dissertações e teses defendidas nos anos de 1990 e 2000. Formação docente - Revista Brasileira de formação de professores, 01(01), 41-56.

Assis, A. E. S. Q. (2007). Especialistas, professores e pedagogos: afinal, que profissional é formado no curso de pedagogia?. Dissertação de Mestrado, Pontifícia Universidade Católica de Campinas, Campinas, São Paulo.

Bauman, Z. (2005). Identidade: entrevista a Benedetto Vecchi. Rio de Janeiro: Jorge Zahar.

Buccini, I. C. (2007). Identidades de educadoras sociais: trajetórias de vida e formação. Dissertação de Mestrado, Universidade de São Paulo, São Paulo.

Ciampa, A. C. (1987). A estória do Severino e a história da Severina. São Paulo: Editora Brasiliense.

Conti, C. L. A. (2003). Imagens da profissão docente: um estudo sobre professoras primárias em início de carreira. Tese de Doutorado, Universidade Estadual de Campinas, Campinas, São Paulo.
Dubar, C. (1997). Para uma teoria sociológica da identidade. Em A socialização. Porto: Porto Editora.

Ferreira, M. A. (2006). Ser-professor: construção de identidade em processo autoformativo. Dissertação de mestrado, Universidade Metodista de São Paulo, São Bernardo do Campo, São Paulo.

Freitas, F. L. (2006). A constituição da identidade docente: discutindo a prática no processo de formação. Dissertação de Mestrado, Universidade Estadual de Campinas, Campinas, São Paulo.

Hall, S. (2006). A identidade cultural na pós-modernidade $\left(11^{\mathrm{a}}\right.$. Edição). São Paulo: DP\&A.

Mercer, K. (1990). Welcome to the jungle. Em J. Ruttherford (Org.), Identity. Londres: Lowrence and Wishart.

Mesquita, I. M. (2008). Memórias/ldentidades em relação ao ensino e formação de professores de história: diálogos com fóruns acadêmicos nacionais. Tese de Doutorado, Universidade Estadual de Campinas, Campinas, São Paulo.

Pagnez, K. S. M. M. (2007). O ser professor no ensino superiorna área da saúde. Tese de Doutorado, Pontifícia Universidade Católica de São Paulo, São Paulo.

Pandolpho, M. M. S. (2006). Ensino de Biologia em questão: os valores e as referências da graduação na prática docente sob o olhar de egressos. Dissertação de Mestrado, Pontifícia Universidade Católica de Campinas, Campinas, São Paulo.

Pereira, G. A. (2007). No fio da história: uma análise da (re) construção identitária de professores - entrecruzando tempos, memórias e espaços. Tese de Doutorado, Pontifícia Universidade Católica do Rio Grande do Sul, Porto Alegre.

Severino, A. J. (2007). Metodologia científica. São Paulo: Cortez.

Vieira, M. M. S. (2009). Tornar-se professor em uma escola confessional: um estudo sobre a constituição identitária na perspectiva da dimensão da espiritualidade. Tese de Doutorado, Pontifícia Universidade Católica de São Paulo, São Paulo.

Recebido em: 10/09/2009

Reformulado em: 22/06/2010 (1 $\left.{ }^{\text {a }}\right)$

Reformulado em: 15/10/2010 (2a)

Aprovado em: 20/01/2011

\section{Sobre os autores}

Ederson de Faria (edersonfaria@yahoo.com.br)

Pontifícia Universidade Católica de Campinas

Vera Lúcia Trevisan de Souza (vera.trevisan@uol.com.br)

\section{Endereço para correspondência:}

Rua Eduardo da Silva Magalhães, 77. Parque Continental. CEP 05324-000 São Paulo - SP. 